\title{
Statins significantly reduce mortality in patients receiving clopidogrel without affecting platelet activation and aggregation: a systematic review and meta- analysis
}

\author{
Ke $A n^{1,2}$, Rong Huang ${ }^{1}$, Sai Tian ${ }^{1}$, Dan Guo ${ }^{1}$, Jiaqi Wang ${ }^{1}$, Hongyan Lin ${ }^{1}$ and Shaohua Wang ${ }^{1 *}$ (D)
}

\begin{abstract}
Background: Combination of statins and clopidogrel is frequently administered in patients with coronary artery disease (CAD). They are mainly activated and eliminated in the liver by cytochrome P450 isoenzyme 3A4 (CYP3A4). The aim was to clarify whether the coadministration of clopidogrel and statins attenuate respective efficacy.

Methods: PubMed, Embase, the Cochrane Library, Web of Science and Clinical Trials. gov were searched for until August 2018. Randomized controlled trials (RCTs) and cohort studies were taken into quality evaluation. Data were pooled using random effect models to estimate standard mean difference (SMD) or risk ratio (RR) with 95\% confidence interval (Cl).

Results: In total, 28 studies representing 25,267 participants were included. Statins reduce the mortality of patients administered clopidogrel (RR $0.54 ; 95 \% \mathrm{Cl} 0.40,0.74 ; p=0.000$ ), no differences were found in platelet aggregation (PA) (SMD 0.02; $95 \% \mathrm{Cl}-0.38,0.42 ; p=0.920$ ) and the expressions of P-selectin (SMD $-0.04 ; 95 \% \mathrm{Cl}-0.14,0.05 ; p=0.346)$, CD40L (SMD 0.09; 95\% Cl -0.29,0.48; $p=0.633$ ), CD63 (SMD 0.09; 95\% Cl -0.01,0.19; $p=0.079$ ) and PAC-1 (SMD 0.03; 95\% Cl -0.08,0.13; $p=0.633)$. Furthermore, CYP3A4 metabolized or non-CYP3A4 metabolized statins have no discrepancies in PA (SMD 0.13; 95\% Cl -0.31,0.58; $p=0.556)$, P-selectin (SMD 0.17; 95\% Cl -0.16,0.51; $p=0310$ ), death (RR 0.89; $95 \% \mathrm{Cl} 0.38,2.07 ; p=0.791$ ), except for triglyceride (TG) (SMD $-0.19 ; 95 \% \mathrm{Cl}-0.33,-0.06 ; p=0.005$ ).

Conclusions: This meta-analysis confirmed that statins reduce mortality in patients undergoing clopidogrel treatment without affecting platelet activation and aggregation.
\end{abstract}

Keywords: Clopidogrel, Statins, Meta-analysis, Mortality, Platelet aggregation, Lipid

\section{Introduction}

Statins, beyond the low-density lipoprotein lowering and high-density lipoprotein raising, are widely used in the medical therapy of coronary artery disease (CAD) for the dramatic reduction of cardiovascular events [1, 2]. In addition, statins are predominantly metabolized by certain cytochrome P450 isoenzyme 3A4 (CYP3A4) (atorvastatin,

\footnotetext{
* Correspondence: gyjwsh@126.com

${ }^{1}$ Department of Endocrinology, Affiliated Zhongda Hospital of Southeast University, No. 87 DingJiaQiao Road, Nanjing 210009, People's Republic of China

Full list of author information is available at the end of the article
}

lovastatin, simvastatin, cerivastatin), whereas others are not substrates of CYP3A4 (pravastatin, rosuvastatin) [3]. Clopidogrel, the most commonly used drug of CAD, is an inactive prodrug requiring oxidation by the hepatic cytochrome P450 isoenzyme system to exert an active metabolite, especially CYP3A4 system, which irreversibly blocks the platelet P2Y12 receptor [4].

Since the concomitant use of clopidogrel and statin is a key element in the therapy of $\mathrm{CAD}$, and given that they share the same metabolic way, there is a growing interest in exploring the potential interaction between clopidogrel and statin on platelet activation, platelet

(C) The Author(s). 2019 Open Access This article is distributed under the terms of the Creative Commons Attribution 4.0 International License (http://creativecommons.org/licenses/by/4.0/), which permits unrestricted use, distribution, and 
aggregation (PA), lipid control, and clinical outcomes. However, available studies on this topic have shown inconsistent and inconclusive findings. Several studies have reported that statins significantly had reduced antiaggregatory effect on clopidogrel, especially CYP3A4 metabolized statins [5-7], whereas some other reports have indicated that therapy with statins did not jeopardize the antiplatelet activity of clopidogrel [8-12]. Furthermore, a number of trials have shown that statins did not have an impact on the clinical outcome of the clopidogrel treatment after percutaneous coronary intervention (PCI) [11, 13-16], while others have noted that patients taking atorvastatin and clopidogrel had the increased risk of major adverse events [17].

Drug interaction affecting either the efficacy or safety of clopidogrel therapy is of paramount importance. Therefore, we conducted this meta-analysis by systematically incorporating the latest evidence with a primary focus on the impacts of antiplatelet function of clopidogrel by the administration of statin in patients with CAD as well as on the investigation of lipid-lowering impact of statin when it was combined with clopidogrel. Moreover, since statins can be divided into CYP3A4 metabolized and non-CYP3A4 metabolized, our secondary aim was to assess whether clopidogrel recipients has distinct response to them. Finally, we address the question of whether statin regimens in combination of clopidogrel can have less clinical outcomes.

\section{Methods}

\section{Data sources and search strategy}

We searched PubMed, EMBASE, the Cochrane Library, Web of Science and Clinical Trials gov for reports published up to August 2018 using the search terms "(clopidogrel OR clopidogrel napadisilate OR platelet aggregation inhibitor OR purinergic P2Y receptor antagonist)" and "(statins OR hydroxymethylglutaryl-CoA reductase inhibitors OR HMGCoA OR lipid lowering drugs OR atorvastatin OR fluvastatin OR lovastatin OR pravastatin OR rosuvastatin OR simvastatin)". We restricted the search to "human species". The searches were not restricted by the date of study publication, language of publication or age of study subjects. The details of search strategy of PubMed was provided in Additional file 1. Reports were further screened for inclusion by reviewing their titles, abstracts, or full texts. We also examined the reference lists of the identified articles previous meta-analyses to supplement the electronic search.

\section{Study selection}

Two independent researchers accessed the articles based on the following inclusion criteria: (1) trials that reported the association between clopidogrel and statins and (2) participants were diagnosed with CAD. Any divergence was resolved by a reviewer.

\section{Data extraction and quality assessment}

For included trials, the following data for each trial were extracted to identify whether the combination of clopidogrel and statin can affect respective efficacy: authors, year of publication, study properties (e.g. study design, sample size, population, intervention) and end points. We also recorded lipid metabolic variables (e.g. parameters of low-density lipoprotein cholesterol [LDL-C], high-density lipoprotein cholesterol [HDL-C], total cholesterol [TC], and triglyceride [TG]) to help understand the lipid-lowering process.

The quality of the cohort studies was evaluated using validated 9-star Newcastle-Ottawa Scale (NOS) [18], which assigns a maximum of 4 stars to the selection category, 2 stars for the comparability category, and 3 stars for the outcome category. Studies with NOS scores $\geq 7$ were considered to be of high quality; otherwise, they were of low quality. The Cochrane Collaboration "Risk of Bias" tool [19], which includes items on selection bias, performance bias, detection bias, attrition bias, and reporting bias, was applied to evaluate the quality of RCTs. More details were presented in Tables 1 and 2. All the data collection and quality assessment were initially performed by one author, and another author checked the extracted data for accuracy.

\section{Results}

Literature search and study characteristics

The literature search results and study selection process are shown in Fig. 1. In total, 3083 potentially suitable articles were identified, where 773 were from PubMed, 1323 from Embase, 634 from Web of Science, 300 from the Cochrane Central Register of Controlled Trials and 53 from ClinicalTrials.gov. The detailed characteristics of these trials are summarized in Table 1 . Of these 28 trials, a total of 25,267 participants were included, with sample sizes ranging from 44 to15693 in individual trials.

\section{Data synthesis and statistical analysis}

The meta-analyses and statistical analyses were undertaken using stata11.0. To overcome a unit-of-analysis error, for studies with multiple intervention groups, numbers of groups were proportional distribution. We analyzed outcomes reported at the last available time point when studies reported outcome variables at different time points throughout the intervention period.

Statistical heterogeneity between studies was evaluated using $\mathrm{I}^{2}$ statistics, and $\mathrm{I}^{2}$ value $>50 \%$ was defined as heterogeneous. We used Cohen's to represent the standardized mean difference (SMD) or risk ratio (RR) for each included study because of the use of different measurement techniques to assess platelet indexes, the SMDs and 95\% confidence intervals (CIs) for each study were pooled using a random-effects model. Funnel plot and the Egger 
Table 1 Characteristics of the 28 clinical trials

\begin{tabular}{|c|c|c|c|c|c|c|c|c|}
\hline Study & Year & Study design & $\begin{array}{l}\text { Sample } \\
\text { size }\end{array}$ & Population & Intervention (mg/d) & $\begin{array}{l}\text { Mean } \\
\text { follow-up }\end{array}$ & End-points & $\begin{array}{l}\text { NOS } \\
\text { score }\end{array}$ \\
\hline Lofti et al. [20] & 2008 & $\mathrm{RCT}$ & 4162 & ACS & $\begin{array}{l}\text { G1: } \mathrm{A} 80+\mathrm{Clo} \\
\text { G2: } 440+\mathrm{Clo}\end{array}$ & 2 years & Death, MI, UA, stroke & - \\
\hline Malmstrom et al. [21] & 2009 & $\mathrm{RCT}$ & 69 & CAD PCl & $\begin{array}{l}\text { G1: R10-40+Clo } \\
\text { G2: A20-80+ Clo } \\
\text { G3: S40 + Clo }\end{array}$ & 16 weeks & $\begin{array}{l}\text { PA, P-selectin, fibrinogen } \\
\text { binding }\end{array}$ & - \\
\hline Mitsios et al. [22] & 2004 & $\mathrm{RCT}$ & 45 & ACS & $\begin{array}{l}\text { G1: A10 + Clo } \\
\text { G2: P40 + Clo }\end{array}$ & 5 weeks & $\begin{array}{l}\text { PA, P-selectin, CD40L, } \\
\text { lipids, ALT, AST, LDH, CK }\end{array}$ & - \\
\hline Neubauer et al. [10] & 2003 & $\begin{array}{l}\text { Prospective } \\
\text { cohort }\end{array}$ & 47 & CAD & $\begin{array}{l}\mathrm{G} 1: \mathrm{S} 10 / \mathrm{S} 20 / \mathrm{A} 20 / \\
\mathrm{A} 40+\mathrm{Clo} \\
\mathrm{G} 2: \mathrm{Clo}\end{array}$ & $48 \mathrm{~h}$ & P-selectin & 9 \\
\hline Ojeifo et al. [23] & 2013 & Cohort & 4794 & ACS & $\begin{array}{l}\text { G1: Statin + Clo } \\
\text { G2: Clo }\end{array}$ & 450 days & $\begin{array}{l}\text { Cardiovascular death, } \\
\text { Ml, stroke }\end{array}$ & 7 \\
\hline Park et al. [24] & 2016 & $\mathrm{RCT}$ & 3755 & $\mathrm{PCl}$ & $\begin{array}{l}\text { G1: CYP3A4 + Clo } \\
\text { G2: non-CYP3A4 + Clo }\end{array}$ & 1 month & $\begin{array}{l}\text { PRU, death, MI, revascularization, } \\
\text { stent thrombosis }\end{array}$ & - \\
\hline Poyet et al. [25] & 2010 & $\mathrm{RCT}$ & 138 & ACS PCI & $\begin{array}{l}\text { G1: A80 + Clo } \\
\text { G2: } \mathrm{R} 20+\mathrm{Clo}\end{array}$ & 1 month & PA, LDL-C, HDL-C, CRP & - \\
\hline Schmidt et al. [26] & 2012 & Cohort & 13,001 & $\mathrm{PCl}$ & $\begin{array}{l}\text { G1: Statin + Clo } \\
\text { G2: Clo }\end{array}$ & 12 months & MACE & 7 \\
\hline Serebruany et al. [6] & 2005 & $\begin{array}{l}\text { Prospective } \\
\text { cohort }\end{array}$ & 75 & $\mathrm{PCl}$ & $\begin{array}{l}\text { G1: A10-40+Clo } \\
\text { G2: other statins + Clo } \\
\text { G3: Clo }\end{array}$ & $24 \mathrm{~h}$ & $\begin{array}{l}\text { PA, P-selectin, CD40L, } \\
\text { CD63, PAC-1 }\end{array}$ & 8 \\
\hline Suh et al. [27] & 2014 & $\begin{array}{l}\text { Prospective } \\
\text { cohort }\end{array}$ & 556 & $\mathrm{PCl}$ & $\begin{array}{l}\mathrm{G} 1: \mathrm{A} 20+\mathrm{Clo} \\
\mathrm{G} 2: \mathrm{R} 10+\mathrm{ClO}\end{array}$ & 6 months & $\begin{array}{l}\text { PRU, lipids, MACE, death, } \\
\text { MI, stent thrombosis, } \\
\text { ischemic strike, target } \\
\text { lesion revascularization }\end{array}$ & 7 \\
\hline Toso et al. [28] & 2017 & Cohort & 1053 & ACS PCI & $\begin{array}{l}\text { G1: Statin + Clo } \\
\text { G2: Clo }\end{array}$ & 1 year & $\begin{array}{l}\text { PRI, MACE, death, } \\
\text { Cardiac death, MI, stent } \\
\text { thrombosis, stroke }\end{array}$ & 7 \\
\hline Vinholt et al. [29] & 2005 & Cohort & 66 & CAD & $\begin{array}{l}\text { G1: CYP3A4 + Clo } \\
\text { G2: non-CYP3A4 + Clo }\end{array}$ & 21 days & PA, TC, LDL-C & 9 \\
\hline Wenaweser et al. [30] & 2010 & $\mathrm{RCT}$ & 101 & CAD PCl & $\begin{array}{l}\text { G1: } \mathrm{A} 40+\mathrm{Clo} \\
\mathrm{G} 2: \mathrm{F} 80+\mathrm{Clo}\end{array}$ & 1 month & PA & - \\
\hline Wenaweser et al. [31] & 2007 & $\mathrm{RCT}$ & 73 & $\mathrm{PCl}$ & $\begin{array}{l}\text { G1: A20/P40+ Clo } \\
\text { G2:Clo }\end{array}$ & 1 month & PA, lipids, CRP & - \\
\hline Zhang et al. [32] & 2015 & $\mathrm{RCT}$ & 104 & NSTE-ACS PCI & $\begin{array}{l}\text { G1: } \mathrm{A} 20+\mathrm{Clo} \\
\text { G2: } \mathrm{Clo}\end{array}$ & 6 months & IPA, P-selectin, TBX 2 sCD40L & - \\
\hline Gorchakova et al. [19] & 2004 & Cohort & 180 & CAD PCl & $\begin{array}{l}\text { G1: A/S + Clo } \\
\text { G2: Clo }\end{array}$ & $\begin{array}{l}\text { At least } 4 \\
\text { weeks }\end{array}$ & $\begin{array}{l}\text { Maximal PA, Residual PA, } \\
\text { P-selectin, CD61 }\end{array}$ & 8 \\
\hline Lim et al. [15] & 2005 & $\begin{array}{l}\text { Prospective } \\
\text { cohort }\end{array}$ & 15,693 & ACS & $\begin{array}{l}\text { G1: statin + Clo } \\
\text { G2: Clo }\end{array}$ & 6 months & $\begin{array}{l}\text { Rehospitalization, stroke, } \\
\text { revascularization, death }\end{array}$ & 9 \\
\hline Nagavi et al. [33] & 2016 & $\begin{array}{l}\text { Prospective } \\
\text { cohort }\end{array}$ & 61 & $\mathrm{PCl}$ & $\begin{array}{l}\text { G1: A40+Clo } \\
\text { G2: R40 + Clo } \\
\text { G3: Clo }\end{array}$ & $24 \mathrm{~h}$ & PA & 7 \\
\hline Riondino et al. [34] & 2009 & Cohort & 105 & $\mathrm{PCl}$ & $\begin{array}{l}\text { G1: A20+Clo } \\
\text { G2: } \mathrm{R} 10+\mathrm{Clo} \\
\text { G3: Clo }\end{array}$ & 3 months & PA & 8 \\
\hline Trenk et al. [11] & 2008 & Cohort & 1395 & $\mathrm{PCl}$ & $\begin{array}{l}\text { G1: A + Clo } \\
\text { G2: S+Clo } \\
\text { G3: F+Clo } \\
\text { G4: P + Clo } \\
\text { G5: Clo }\end{array}$ & 1 year & $\begin{array}{l}\text { RPA, P-selectin, CD63, PAC-1, } \\
\text { MACE, death, MI, target lesion } \\
\text { reintervention }\end{array}$ & 7 \\
\hline Mitsios et al. [35] & 2005 & Cohort & 51 & ACS PCI & $\begin{array}{l}\mathrm{G} 1: \mathrm{A}+\mathrm{Clo} \\
\mathrm{G} 2: \mathrm{Clo}\end{array}$ & 5 weeks & PA, P-selectin, CD40L & 7 \\
\hline Mukherjee et al. [36] & 2005 & $\begin{array}{l}\text { Prospective } \\
\text { cohort }\end{array}$ & 1651 & ACS & $\begin{array}{l}\text { G1: CYP3A4 + Clo } \\
\text { G2: non-CYP3A4 + Clo } \\
\text { G3: Clo }\end{array}$ & 6 months & death, Ml, stroke, MACE & 8 \\
\hline
\end{tabular}


Table 1 Characteristics of the 28 clinical trials (Continued)

\begin{tabular}{|c|c|c|c|c|c|c|c|c|}
\hline Study & Year & Study design & $\begin{array}{l}\text { Sample } \\
\text { size }\end{array}$ & Population & Intervention (mg/d) & $\begin{array}{l}\text { Mean } \\
\text { follow-up }\end{array}$ & End-points & $\begin{array}{l}\text { NOS } \\
\text { score }\end{array}$ \\
\hline Lau et al. [4] & 2003 & $\begin{array}{l}\text { Prospective } \\
\text { cohort }\end{array}$ & 44 & $\mathrm{PCl}$ & $\begin{array}{l}\text { G1: A + Clo } \\
\text { G2: P + Clo } \\
\text { G3: Clo }\end{array}$ & $24 \mathrm{~h}$ & PA & 8 \\
\hline Matetzky et al. [37] & 2010 & Cohort & 120 & STEMI & $\begin{array}{l}\text { G1: statin + Clo } \\
\text { G2: Clo }\end{array}$ & $72 \mathrm{~h}$ & PA & 9 \\
\hline Brophy et al. [16] & 2006 & $\begin{array}{l}\text { Retrospective } \\
\text { cohort }\end{array}$ & 2927 & $\mathrm{PCl}$ & $\begin{array}{l}\text { G1: A+Clo } \\
\text { G2: Clo }\end{array}$ & 30 days & $\begin{array}{l}\text { death, MI, UA, repeat } \\
\text { revascularizations, } \\
\text { stroke, transient } \\
\text { ischemic attack }\end{array}$ & 7 \\
\hline Pelliccia et al. [38] & 2014 & $\mathrm{RCT}$ & 122 & $C A D$ & $\begin{array}{l}\text { G1: } \mathrm{A} 40+\mathrm{Clo} \\
\text { G2: } \mathrm{R} 20+\mathrm{Clo}\end{array}$ & 30 days & PRU, lipids & - \\
\hline J.-M.Lablanche et al. [39] & 2010 & $\mathrm{RCT}$ & 753 & ACS & $\begin{array}{l}\text { G1: A80 + Clo } \\
\text { G2: R20 + Clo }\end{array}$ & 3 months & $\begin{array}{l}\text { lipids, Ml, stroke, } \\
\text { death, UA, repeat } \\
\text { revascularization }\end{array}$ & - \\
\hline Guo et al. [40] & 2017 & $\mathrm{RCT}$ & 137 & ACS PCl & $\begin{array}{l}\text { G1: R10+Clo } \\
\text { G2: Clo }\end{array}$ & 1 year & $\begin{array}{l}\text { Restenosis, death, } \\
\text { Ml, target vessel } \\
\text { revacularization }\end{array}$ & - \\
\hline
\end{tabular}

G: group; RCT: randomized controlled trial; ACS: acute coronary syndromes; CAD: coronary artery disease; MI: myocardial infarction; UA: unstable angina; PCl: percutaneous coronary intervention; PA: platelet aggregation; PRU: platelet reactive unit; LDL-C: low-density lipoprotein cholesterol; HDL-C: high-density lipoprotein cholesterol; TC: total cholesterol; CRP: C-reactive protein; MACE: major adverse cardiovascular events; A: atorvastatin; P: P:pravastatin; R:rosuvastatin; F:fluvastatin; Clo: clopidogrel

test were used to test for publication bias. A 2-sided $\mathrm{P}<0.05$ was considered statistically significant. More details of results of partial negative effect, sensitivity analysis and publication bias of included trials were displayed in Additional files 2, 3 and 4 .

\section{Meta-analysis 1: statin + clopidogrel versus clopidogrel Effect on PA indicator}

Among the 17 studies comparing the effects of statin and clopidogrel versus clopidogrel, 8 detected data (363 statin group, 273 control group) on PA (Fig. 2a). The superiority of statin plus clopidogrel was not confirmed (SMD 0.02; 95\% CI $-0.38,0.42 ; p=0.920$ ) with significant heterogeneity $\left(\mathrm{I}^{2}=77.1 \%, p=0.000\right)$.

\section{Effect on residual platelet aggregation (RPA)indicator}

Of the 17 trials in the statin plus clopidogrel versus clopidogrel, 2 provided data on the RPA. No significant difference was observed (SMD -0.02; 95\% CI $-0.10,0.07 ; p=0.700)$. No heterogeneity was detected in $\mathrm{RPA}\left(\mathrm{I}^{2}=6.8 \%, p=0.368\right)$.

\section{Effect on P-selectin(CD62P) indicator}

6 trials were identified among the included 17 trials. No reduction was observed in the P-selectin (SMD $-0.04 ; 95 \%$ CI $-0.14,0.05 ; p=0.346)$. However, no heterogeneity was observed in the level of P-selectin $\left(\mathrm{I}^{2}=0.0 \%, p=0.858\right)$.

Table 2 Quality assessment of the randomized controlled trials

\begin{tabular}{|c|c|c|c|c|c|c|c|}
\hline Study & $\begin{array}{l}\text { Random sequence } \\
\text { generation }\end{array}$ & $\begin{array}{l}\text { Allocation } \\
\text { concealment }\end{array}$ & $\begin{array}{l}\text { Blinding of } \\
\text { participants }\end{array}$ & $\begin{array}{l}\text { Blinding of } \\
\text { outcome }\end{array}$ & $\begin{array}{l}\text { Incomplete outcome } \\
\text { data addressed }\end{array}$ & $\begin{array}{l}\text { Non-elective } \\
\text { reporting }\end{array}$ & $\begin{array}{l}\text { Other } \\
\text { bias }\end{array}$ \\
\hline Lofti et al. [20] (PROVE-IT) & U & $U$ & L & L & L & L & L \\
\hline Malmstrom et al. [21] & $U$ & $U$ & $U$ & L & L & L & L \\
\hline Mitsios et al. [22] & $U$ & U & $U$ & U & L & L & L \\
\hline Park et al. [24] & U & U & L & L & L & L & L \\
\hline Poyet et al. [25] (OSCAR) & U & $U$ & $U$ & U & L & L & L \\
\hline Wenaweser et al. [30] & $U$ & U & L & L & L & $U$ & L \\
\hline Wenaweser et al. [31] & U & U & $U$ & U & L & L & $U$ \\
\hline Zhang et al. [32] & L & L & $U$ & U & L & L & L \\
\hline Pelliccia et al. [38] & U & $U$ & $U$ & U & L & L & $U$ \\
\hline $\begin{array}{l}\text { J.-M.Lablanche et al. [39] } \\
\text { (CENTAURUS) }\end{array}$ & L & L & L & U & L & L & L \\
\hline Guo et al. [40] & U & $U$ & $U$ & U & L & L & $\mathrm{H}$ \\
\hline
\end{tabular}




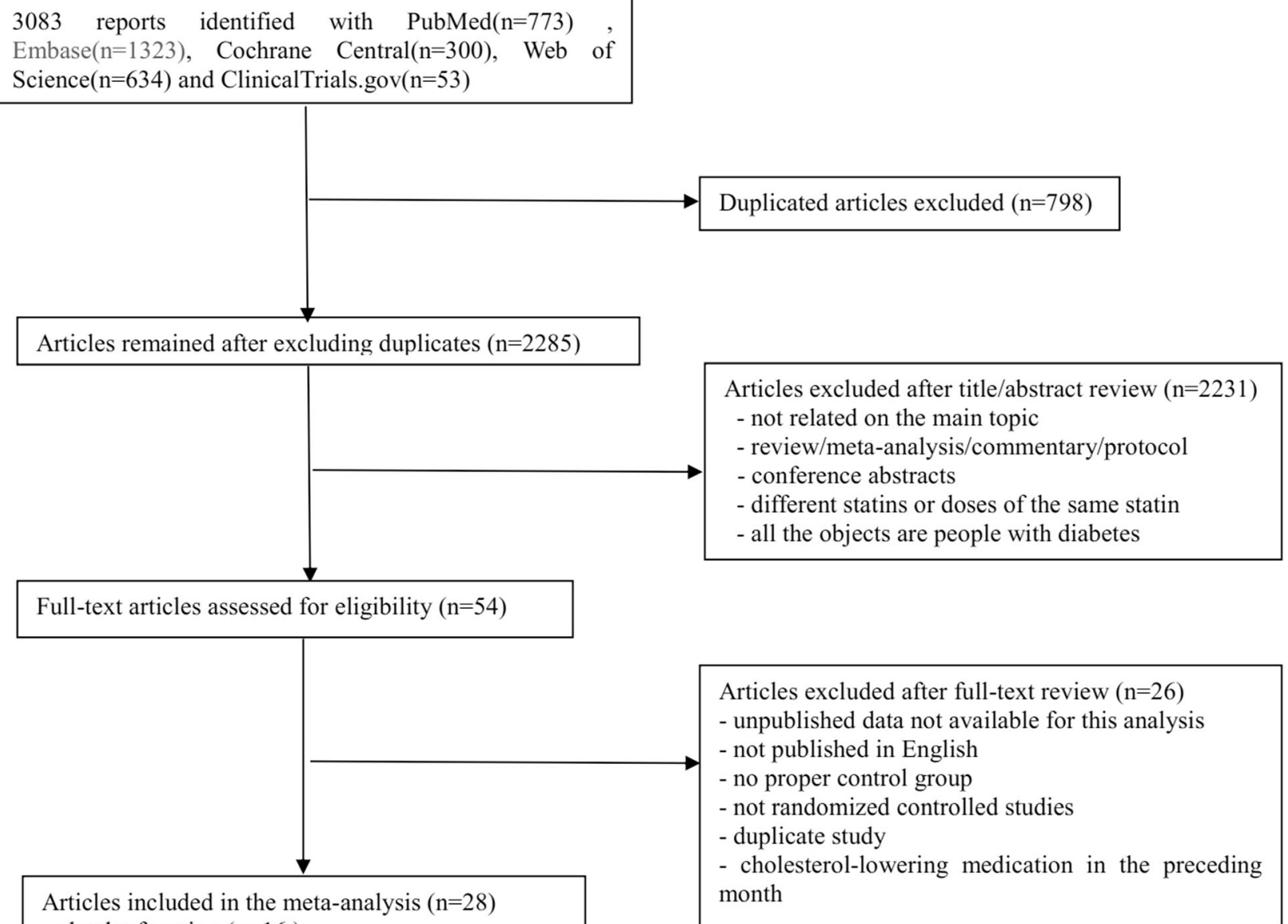

Fig. 1 Flow diagram

\section{Effect on CD40L, CD63 (LAMP-3),PAC-1 indicators}

3 trials detected data on $\mathrm{CD} 40 \mathrm{~L}$, while 2 studies provided data on CD63 and PAC-1. No change was found in the following: CD40L (SMD 0.09; 95\% CI -0.29,0.48; $p=0.633$ ), CD63 (SMD 0.09; 95\% CI $-0.01,0.19 ; p=0.079$ ), PAC-1 (SMD 0.03; 95\% CI -0.08,0.13; $\mathrm{p}=0.633$ ). No heterogeneities were detected in CD40L $\left(\mathrm{I}^{2}=22.1 \%, p=0.274\right)$, CD63 $\left(\mathrm{I}^{2}=0.0 \%, p=0.916\right)$, PAC- $1\left(\mathrm{I}^{2}=0.0 \%, p=0.650\right)$.

\section{Effects on clinical outcomes (including death, MI [myocardial infarction], stroke, MACE[major adverse cardiovascular events])}

Death event was recorded in the 6 trials (Fig. 2b). The benefit of clopidogrel was significantly influenced of concomitant treatment with a statin and this was irrespective of treatment with CYP3A4 metabolized statin (RR 0.54; 95\% CI 0.40,0.74; $p=0.000$ ) with no heterogeneity $\left(\mathrm{I}^{2}=0.0 \%, p=0.735\right)$.
5 trials with 5346 participants provided the incidence of MI. The pooled estimates of trials demonstrated that no difference was found (RR 1.0; 95\% CI 0.67,1.48; $p=$ $0.994)$ with no heterogeneity $\left(\mathrm{I}^{2}=0.0 \%, p=0.675\right)$.

Stroke was reported in 5 studies with 1 trial missing data. The combined therapy failed to reduce the occurrence of stroke (RR 0.98; 95\% CI 0.60,1.60; $p=0.944$ ). Heterogeneity was not observed $\left(\mathrm{I}^{2}=3.4 \%, p=0.376\right)$.

MACE was identified in 4 trials (Fig. 2c). No difference was found (RR $0.79 ; 95 \%$ CI $0.63,1.00 ; p=0.047$ ) with no heterogeneity $\left(\mathrm{I}^{2}=0.0 \%, p=0.476\right)$.

Meta-analysis 2: CYP3A4 metabolized statin + clopidogrel versus non-CYP3A4 metabolized statin + clopidogrel Effect on PA indicator

A total of 10 clinical studies involving 1279 participants 874 CYP3A4 metabolized, 405 non-CYP3A4 metabolized were included in the analysis to investigate the effect of different type of statin (Fig. 3a). The overall pooled mean difference 


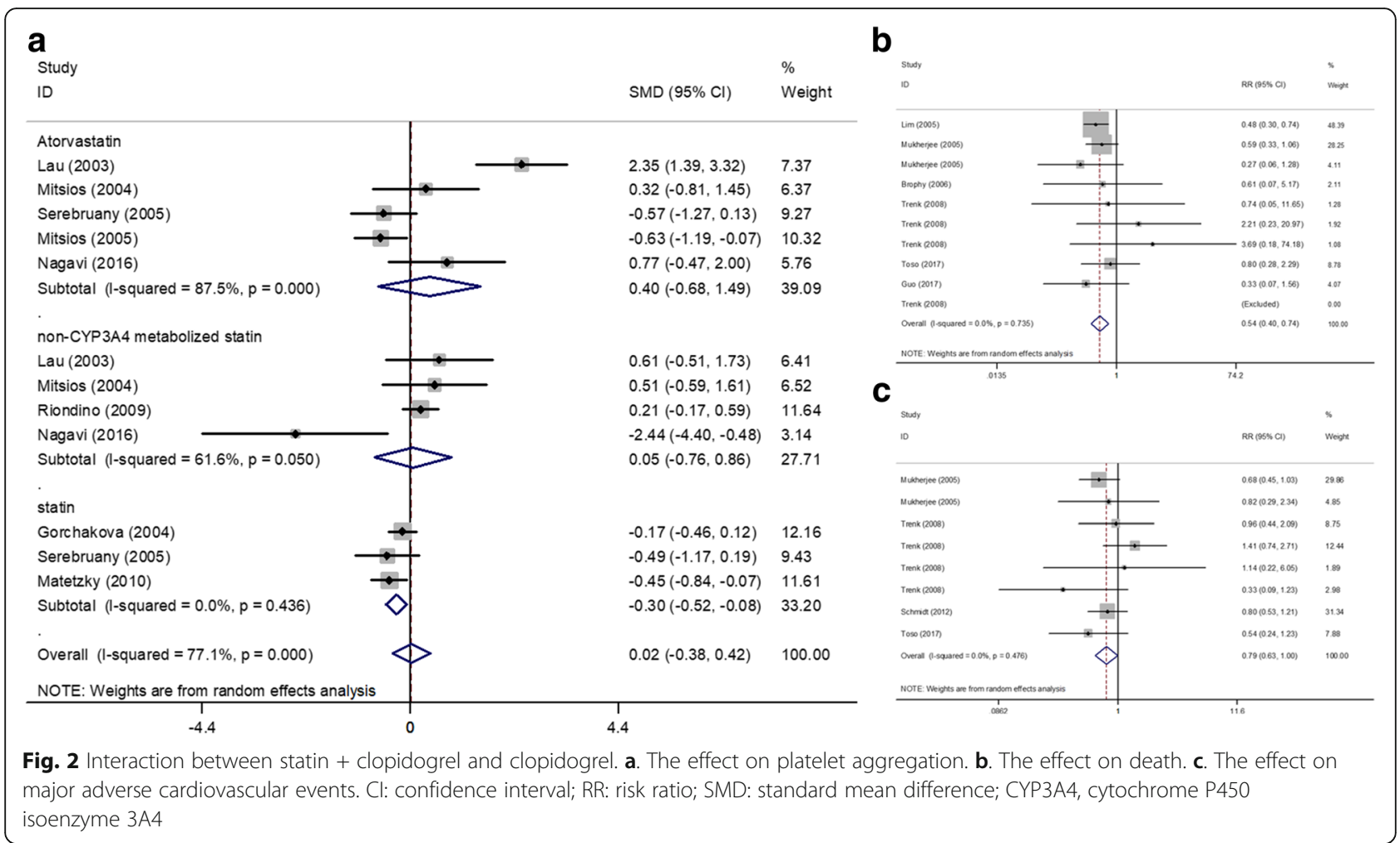

on PA was 0.13 (SMD 0.13; 95\% CI -0.31,0.58; $p=0.556$ ). However, different research types showed high heterogeneity $\left(\mathrm{I}^{2}=90.0 \%, p=0.000\right)$.

\section{Effect on P-selectin(CD62P) indicator}

A total of 4 trials with 5 comparisons involved 840 patients (651 assigned to CYP3A4 metabolized statin therapy, 189 assigned to non-CYP3A4 metabolized statin therapy) reported the effect on P-selectin. The overall pooled mean difference on P-selectin was 0.17 (SMD 0.17 ; $95 \%$ CI $-0.16,0.51 ; p=0.310)$ with low heterogeneity $\left(\mathrm{I}^{2}=65.8 \%, p=0.020\right)$. However, RCTs showed significant difference on P-selectin (SMD 0.52; 95\% CI $-0.17,0.88 ; p=0.004)$, while cohort study showed no difference (SMD -0.13; 95\% CI -0.33,0.06; $p=0.186$ ).

\section{Effect on lipid metabolism indicators}

Among the 7 studies comparing the effects of lipids, 6, 5,5 and 4 detected data on the changes in LDL-C, HDL-C and TC level respectively. No reduction was observed in the following: LDL-C (SMD 0.02; 95\% CI $-0.35,0.40 ; \quad p=0.900)$, HDL-C (SMD $-0.55 ; 95 \%$ CI $-1.15,0.04 ; \quad p=0.069)$, TC (SMD $-0.04 ; 95 \%$ CI $0.25,0.17 ; p=0.723)$. Compared to non-CYP3A4 metabolized statin, the CYP3A4 metabolized statin remarkably decreased the TG level (SMD -0.19; 95\% CI -0.33,-0.06; $p=0.005)$ with no heterogeneity $\left(\mathrm{I}^{2}=24.1 \%, p=0.267\right)$ (Fig. 3b). Heterogeneities were detected in LDL-C
$\left(\mathrm{I}^{2}=90.3 \%, p=0.000\right), \mathrm{HDL}-\mathrm{C}\left(\mathrm{I}^{2}=96.1 \%, \mathrm{p}=0.000\right)$, HDL-C $\left(\mathrm{I}^{2}=96.1 \%, \mathrm{p}=0.000\right), \mathrm{TC}\left(\mathrm{I}^{2}=64.6 \%, p=0.023\right)$.

\section{Effect on clinical outcomes(including death, MI, stroke and MACE)}

The incidence of death was reported in 5 studies with 1 missing data. Compared to non-CYP3A4 metabolized statins, CYP3A4 metabolized statins did not reduce mortality (RR $0.89 ; 95 \%$ CI $0.38,2.07 ; p=0.791$ ) with no heterogeneity $\left(\mathrm{I}^{2}=20.7 \%, p=0.283\right)$.

MI data were provided in 5 studies with 1 missing data. The pooled effect demonstrated that no difference was found (RR 0.82; 95\% CI 0.52,1.28; $p=0.377$ ) with no heterogeneity $\left(\mathrm{I}^{2}=0.0 \%, p=0.575\right)$.

Stroke was reported in 3 studies. Compared to non-CYP3A4 metabolized statin plus clopidogrel, the CYP-3A4 metabolized statin therapy combined clopidogrel failed to reduce the incidence of stroke (RR 0.86; 95\% CI 0.13,5.61; $p=0.875$ ).

MACE was recorded in 4 trials. The pooled effect was found no difference (RR 0.95; 95\% CI 0.68,1.34; $p=$ 0.788).

\section{Discussion}

Our meta-analysis revealed that in patients receiving concomitantly statin and clopidogrel, statins significantly reduced mortality and MACE without affecting platelet activation and aggregation. Furthermore, CYP3A4 


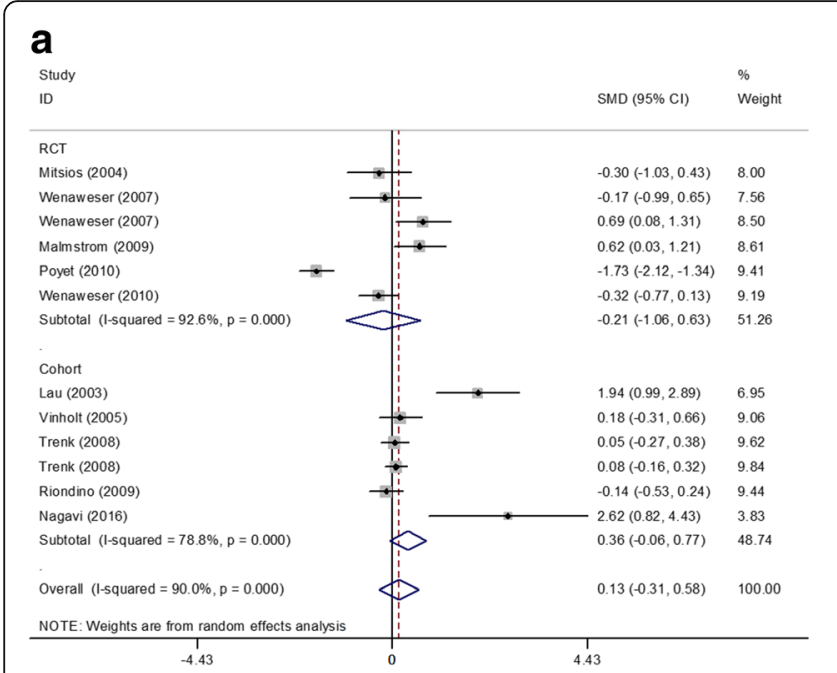

b

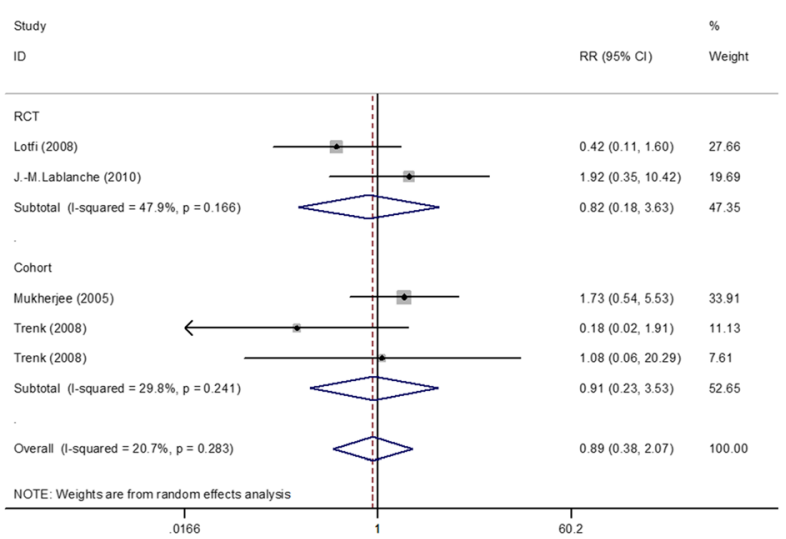

Fig. 3 Interaction between CYP3A4 statin + clopidogrel and non-CYP3A4 statin + clopidogrel a. The effect on platelet aggregation. $\mathbf{b}$. The effect on death. Cl: confidence interval; SMD: standard mean difference; RCT, randomized controlled trial metabolized and non-CYP3A4 metabolized statins had similar influence on platelet activity, lipid metabolism and clinical outcomes, except for TG level. CYP3A4 metabolized statins more greatly reduced the level of TG than CYP3A4 metabolized statins.

The effect of combination of statin plus clopidogrel on platelet activity have aroused people's concern. Lau et al. first reported the negative interference of atorvastatin with the antiplatelet effect of clopidogrel [6]. And some other trials also drove the same result [22, 34, 35]. In contrast, Serebruany et al. showed no difference in platelet inhibitory effects of clopidogrel in patients undergoing coronary stent placement taking statins [10]. And other studies [8, $12,33,37,41-43]$, in accordance with our results, also showed neutral effects of statin on platelet inhibition by clopidogrel. Even more, the main finding of ACHIDO (Atorvastatin and Clopidogrel High DOse in stable patients with residual high platelet activity) study was that high-dose statin improved the pharmacodynamic effects of $150 \mathrm{mg}$ clopidogrel [44]. Possible explanations for this discrepancy could be attributed to the small sample size, lack of strict inclusion criteria, indirect methods for assessment of platelet function and different responses to clopidogrel among patients. Patients with diabetes were often low responders to clopidogrel $[21,45,46]$.

Our meta-analysis not only compared the antiplatelet efficacy of statin plus clopidogrel, but also detected the difference between CYP3A4 metabolized statin and non-CYP3A4 metabolized statin on PA parameters. But the comparison between two groups failed to find statistical difference. A prospective, randomized study also concluded the same result that no difference was found between atorvastatin and fluvastatin treatment arms [47]. And the result was in accordance with some other trials
[30, 42, 48, 49]. However, Neubauer et al. concluded that simvastatin and atorvastatin appear to significantly inhibit the activation of clopidogrel after administration of a loading dose, which reduced by $29.3 \%$ at $5 \mathrm{~h}, 16.6 \%$ at $48 \mathrm{~h}$. And some related researches in healthy people also drove the same conclusion [50,51]. Increasing evidence represented no potential influence of statin on the antiaggregatory effect of clopidogrel, regardless of the type of statins. Several studies assessed RPA also drove the same result that residual ADP-induced platelet aggregation was not significantly different between statin-treatment group and statin naïve group, neither CYP3A4 metabolized statin nor non-CYP3A4 metabolized statin [13, 21, 37].To reflect the multiple effects of $\mathrm{P} 2 \mathrm{Y} 12$ receptor activation on platelet responses, platelet activation markers like granular membrane protein 140 (P-selectin), human soluble cluster of differentiation 40 ligand (sCD40L), CD63 (LAMP-3), PAC-1 were also measured. P-selectin [32], a glycoprotein located in blood platelets and endothelial cells, is a specific molecular marker for platelet activation. When platelets are activated, the P-selectin concentrations on the platelet membranes in plasma are increased. CD40L is a type II membrane protein-transporting molecule expressed by active platelet. After activation, CD40L is released into blood in a soluble manner. In general, no statistical difference was observed when patients administered with statin and clopidogrel, regardless of types of statin. For one thing, clopidogrel can be converted to active metabolites by many isozymes, including CYP 3A4, CYP3A5, CYP1A, CYP2B. For another, the plasma concentration of statin is not enough to reach the saturation of enzyme concentration to cause competitive inhibition. What is more, the expression of inflammatory mediators in ACS is higher than non-ACS, which could promote platelet aggregation. 
However, statins have a strong anti-inflammatory effect. Even with competitive inhibition, it may be compensated by the anti-inflammatory effect of statin [52]. Finally, it should not be ignored that so many factors can weaken curative effect of clopidogrel, like gene polymorphism, hyperinsulinemia or insulin resistance [27, 53-55].

We also detected the interaction between statin and clopidogrel on the aspect of lipid levels, and no statistic influence on lipids level was observed, except for TG level. Four randomized and placebo-controlled trials [20, $25,38,39]$ compared lipid variables in LDL-C and HDL-C between atorvastatin and rosuvastatin and no differences were found. Serebruany et al. general described that TC levels were lower in patients treated with a statin than in those receiving no statin [10]. It is a pity that few articles did deeply into the specific lipid-lowering effect of clopidogrel on statin. Thus, more studies regarding the effects of the lipid parameters were needed to determine whether clopidogrel can decrease lipid levels to perfect the interaction between clopidogrel and statins.

In addition, our study elaborated the impact of combined statin and clopidogrel on clinical outcomes and found that the incidence of death was remarkably decreased. However, other adverse events including stroke, MI were not decreased. Our finding is in accordance with the PROVE IT-TIMI 22 (Pravastatin or Atorvastatin Evaluation and Infection Therapy-Thrombolysis in Myocardial Infarction 22) trial which showed that statin therapy ameliorate long-term clinical events, whether patients taking atorvastatin or pravastatin, which included $>72 \%$ did receive clopidogrel, although clopidogrel was not mandated [56]. Our data also concur with GRACE (Global Registry of Acute Coronary Events), MITRA PLUS (Maximal Individual Therapy of Acute Myocardial Infarction PLUS) and TRITON-TIMI 38 (Trial to Assess Improvement in Therapeutic Outcomes by Optimizing Platelet Inhibition With Prasugrel-Thrombolysis In Myocardial Infarction 38)., suggesting that the combination of clopidogrel with a stain was not related to an increased risk of end points [11, 16, 24]. One crude cohort study reported that no difference was found in the composite of death, MI, any revascularization [57]. And another cohort study also indicated that statin was not associated with an increased early risk of adverse cardiovascular events [36]. From above, additional statin should inevitably be used to obtain better clinical benefits. And our result showed that the treatment of clopidogrel with CYP3A4 metabolized or non-CYP3A4 metabolized statin has no specific difference. A post-hoc analysis of the CREDO trial, reported that statin combined with clopidogrel significantly reduced cardiovascular events compared with clopidogrel alone $[14,15]$. The adverse clinical effect did not differ between the group using clopidogrel either with a statin metabolized by CYP3A4 or a statin not metabolized through CYP3A4. In parallel with our meta-analysis, Mukherjee et al. reported that no statistically significant difference was noted in MACE, stroke, MI, or death at 6 months between those receiving a CYP3A4 metabolized or non-CYP3A4 metabolized statin with clopidogrel therapy [26]. CHARISMA (Clopidogrel for High Atherothrombotic Risk and Ischemic Stabilization, Management, and Avoidance), a large randomized prospective trial which includes 15,574 patients, found that long-term concomitant clopidogrel and statin therapy was associated with a lower primary efficacy end points (MI, stroke, or cardiovascular death)As can be seen from above studies, these studies are different in study design and are not reasonable. The number of cases treated with a single type of statin is still small and the follow-up time is relatively short. However, these results most suggest that combination of statin and clopidogrel should be applied to maximize the cardiovascular benefits, regardless of the statin type, for the reason that the advantage outweigh the disadvantage.

This meta-analysis has several strengths. First, it is to date the most comprehensive analysis that systematically and quantitatively assess the correlation between statins and clopidogrel. Second, indexes to assess the progression of platelet activation and aggregation are taken into consideration. Third, lipid metabolism levels are enriched in this meta-analysis. Furthermore, many clinical outcomes are considered.

This meta-analysis also has several limitations. First, as with any meta-analysis, the internal validity depends on the methodological quality of the included studies. There is unfortunately no one ideal test that will directly indicate the in vivo antiplatelet effect and predict the clinical consequences. Second, the duration of follow-up varied among the included patients and heterogeneities existed among trials. Third, despite no significant publication bias was detected by the Begg's test and Egger's test for each result, the risk of publication bias still cannot be fully ruled out due to the language restriction to English. Additionally, the absence of standardization in study design, characteristics of the study populations were not uniformed. Last but not least, Impaired response to antiplatelet therapy in diabetic patients has been reported. Thus, further prospective studies are warranted to clarify the potential interactions between clopidogrel and statins and to determine whether a true clinical effect exists.

\section{Conclusion}

Statins reduce mortality in patients undergoing clopidogrel treatment without affecting platelet activation and aggregation, either with CYP-3A4 metabolized statin or non-CYP3A4 metabolized statin. However, the level of 
TG is reduced when people administered with clopidogrel and CYP3A4 metabolized statin, compared to non-CYP3A4 metabolized statin. The effect of clopidogrel on lipid parameters and clinical outcomes of people receiving statin is still unknown. Further researches are needed to elucidate the mutual interaction between statin and clopidogrel on more aspects.

\section{Additional file}

Additional file 1: Search strategy of PubMed. (DOCX $17 \mathrm{~kb})$

Additional file 2: Results of sensitivity analysis. (DOCX $11093 \mathrm{~kb}$ )

Additional file 3: Results of publication bias of included trials. (DOCX 26703 kb)

Additional file 4: Contents. (DOCX $34172 \mathrm{~kb}$ )

\section{Abbreviations}

ACS: acute coronary syndrome; CAD: coronary artery disease; Cl: Confidence interval; CYP3A4: cytochrome P450 isoenzyme 3A4; HDL-C: high-density lipoprotein cholesterol; LDL-C: low-density lipoprotein cholesterol; MACE: major adverse cardiovascular events; MI: myocardial infarction; PA: platelet aggregation; RCT: randomized controlled trial; RR: risk ratio; SMD: standard mean difference; TC: total cholesterol; TG: triglycerides

\section{Acknowledgments}

Not applicable.

\section{Funding}

This work was partially supported by the National Natural Science Foundation of China (No.81570732, Shaohua Wang and No.81870568, Shaohua Wang).

\section{Availability of data and materials}

Data are available from the authors on request.

\section{Authors' contributions}

SHW conceived and designed the research, SHW and KA acquired the data, performed statistical analysis, drafted, revised and approved the manuscript submitted. SHW, RH and ST performed this study. All authors read and approved the final manuscript.

\section{Ethics approval and consent to participate}

Not applicable.

\section{Consent for publication}

Not applicable.

\section{Competing interests}

The authors declare that they have no competing interests.

\section{Publisher's Note}

Springer Nature remains neutral with regard to jurisdictional claims in published maps and institutional affiliations.

\section{Author details}

'Department of Endocrinology, Affiliated Zhongda Hospital of Southeast University, No. 87 DingJiaQiao Road, Nanjing 210009, People's Republic of China. ${ }^{2}$ Medical School of Southeast University, Nanjing 210009, People's Republic of China.
Received: 6 March 2019 Accepted: 15 April 2019

Published online: 24 May 2019

\section{References}

1. Schomig A, Mehilli J, Holle $\mathrm{H}$, et al. Statin treatment following coronary artery stenting and one-year survival. J Am Coll Cardiol 2002;40(5):854-861. PubMed PMID: 12225707.

2. Sotiriou CG, Cheng JW. Beneficial effects of statins in coronary artery disease--beyond lowering cholesterol. Ann Pharmacother 2000;34(12):14321439. doi: https://doi.org/10.1345/aph.10124. PubMed PMID: 11144702.

3. Neuvonen PJ. Drug interactions with HMG-CoA reductase inhibitors (statins): the importance of CYP enzymes, transporters and pharmacogenetics Current opinion in investigational drugs 2010;11(3):323332. PubMed PMID: 20178046.

4. Savi P, Pereillo JM, Uzabiaga MF, et al. Identification and biological activity of the active metabolite of clopidogrel. Thromb Haemost 2000;84(5):891896. PubMed PMID: 11127873.

5. Clarke TA, Waskell LA. The metabolism of clopidogrel is catalyzed by human cytochrome P450 3A and is inhibited by atorvastatin [article]. Drug Metab Dispos 2003;31(1):53-59. doi: https://doi.org/10.1124/dmd.31.1.53. English.

6. Lau WC, Waskell LA, Watkins PB, et al. Atorvastatin reduces the ability of clopidogrel to inhibit platelet aggregation: a new drug-drug interaction [Clinical Trial; Journal Article; Randomized Controlled Trial; Research Support, Non-U.S. Gov't; Research Support, U.S. Gov't, Non-P.H.S.; Research Support, U.S. Gov't, P.H.S.]. Circulation. 2003;107(1):32-37. PubMed PMID: CN-00412597.

7. Neubauer H, Günesdogan B, Hanefeld C, et al. Lipophilic statins interfere with the inhibitory effects of clopidogrel on platelet function--a flow cytometry study [clinical trial; controlled clinical trial; journal article]. Eur Heart J 2003;24(19):1744-1749. PubMed PMID: CN-00458047.

8. Müller I, Besta F, Schulz C, et al. Effects of statins on platelet inhibition by a high loading dose of clopidogrel [clinical trial; journal article; randomized controlled trial; research support, non-U.S. Gov't]. Circulation. 2003;108(18): 2195-2197. doi: https://doi.org/10.1161/01.CIR.0000099507.32936.C0. PubMed PMID: CN-00458346.

9. Serebruany VL, Malinin Al, Callahan KP, et al. Statins do not affect platelet inhibition with clopidogrel during coronary stenting. Atherosclerosis. 2001; 159(1):239-241. PubMed PMID: 11689228; eng.

10. Serebruany $\mathrm{VL}$, Midei MG, Malinin Al, et al. Absence of interaction between atorvastatin or other statins and clopidogrel: results from the interaction study. Arch Intern Med 2004;164(18):2051-2057. doi: https://doi.org/10.1001/ archinte.164.18.2051. PubMed PMID: 15477442; eng.

11. Wienbergen $H$, Gitt AK, Schiele R, et al. Comparison of clinical benefits of clopidogrel therapy in patients with acute coronary syndromes taking atorvastatin versus other statin therapies. Am J Cardiol 2003;92(3):285-288. doi: https://doi.org/10.1016/s0002-9149(03)00626-x. PubMed PMID: WOS: 000184503800009

12. Pinheiro LFM, Izar MC, Franca CN, et al. Pharmacokinetic interactions between clopidogrel and rosuvastatin: effects on vascular protection in subjects with coronary heart disease. European Heart Journal. 2012;33:747. PubMed PMID: WOS:000308012405346.

13. Trenk D, Hochholzer W, Frundi D, et al. Impact of cytochrome P450 3A4metabolized statins on the antiplatelet effect of a 600-mg loading dose clopidogrel and on clinical outcome in patients undergoing elective coronary stent placement. Thromb Haemost 2008:99(1):174-181. doi: https://doi.org/10.1160/th07-08-0503. PubMed PMID: WOS: 000252670400024

14. Saw J, Brennan DM, Steinhubl SR, et al. Lack of evidence of a clopidogrelstatin interaction in the CHARISMA trial. J Am Coll Cardiol 2007;50(4):291295. doi: https://doi.org/10.1016/j.jacc.2007.01.097. PubMed PMID: WOS: 000248251800001

15. Saw J, Steinhubl SR, Berger PB, et al. Lack of adverse clopidogrel-atorvastatin clinical interaction from secondary analysis of a randomized, placebo-controlled clopidogrel trial [clinical trial; journal article; randomized controlled trial; research support, non-U.S. Gov't]. Circulation. 2003;108(8):921-924. doi: https://doi.org/10. 1161/01.CIR.0000088780.57432.43. PubMed PMID: CN-00559049.

16. Lim MJ, Spencer FA, Gore JM, et al. Impact of combined pharmacologic treatment with clopidogrel and a statin on outcomes of patients with nonST-segment elevation acute coronary syndromes: perspectives from a large multinational registry [article]. Eur Heart J 2005;26(11):1063-1069. doi: https://doi.org/10.1093/eurheartj/ehi139. English. 
17. Brophy JM, Babapulle MN, Costa V, et al. A pharmacoepidemiology study of the interaction between atorvastatin and clopidogrel after percutaneous coronary intervention [article]. Am Heart J 2006;152(2):263-269. doi: https:// doi.org/10.1016/j.ahj.2005.08.023. English.

18. Stang A. Critical evaluation of the Newcastle-Ottawa scale for the assessment of the quality of nonrandomized studies in meta-analyses. Eur J Epidemiol 2010 Sep;25(9):603-605. doi: https://doi.org/10.1007/s10654-0109491-z. PubMed PMID: 20652370.

19. Higgins JPT, Green S, Cochrane Collaboration. Cochrane handbook for systematic reviews of interventions. Chichester, England; Hoboken, NJ: Wiley-Blackwell; 2008. (Cochrane book series).

20. Pelliccia F, Rosano G, Marazzi G, et al. Pharmacodynamic effects of atorvastatin versus rosuvastatin in coronary artery disease patients with normal platelet reactivity while on dual antiplatelet therapy--the PEARL randomized cross-over study [comparative study; journal article; randomized controlled trial]. Eur J Pharmacol 2014;725:18-22. doi: https://doi.org/10. 1016/j.ejphar.2014.01.006. PubMed PMID: CN-00978298.

21. Geisler T, Zurn C, Paterok M, et al. Statins do not adversely affect postinterventional residual platelet aggregation and outcomes in patients undergoing coronary stenting treated by dual antiplatelet therapy. Eur Heart J. 2008 Jul;29(13):1635-1643. doi: https://doi.org/10.1093/eurhearti/ehn212. PubMed PMID: 18503057; eng

22. Matetzky S, Fefer P, Shenkman B, et al. Statins have an early antiplatelet effect in patients with acute myocardial infarction. Platelets. 2011:22(2):103110. doi: https://doi.org/10.3109/09537104.2010.512402. PubMed PMID: WOS:000286992200004.

23. Leoncini M, Toso A, Maioli M, et al. Early high-dose rosuvastatin and cardioprotection in the protective effect of rosuvastatin and antiplatelet therapy on contrast-induced acute kidney injury and myocardial damage in patients with acute coronary syndrome (PRATO-ACS) study [journal article: randomized controlled trial]. Am Heart J 2014;168(5):792-797. doi: https:// doi.org/10.1016/j.ahj.2014.08.005. PubMed PMID: CN-01022411.

24. Ojeifo O, Wiviott SD, Antman EM, et al. Concomitant administration of clopidogrel with statins or calcium-channel blockers: insights from the TRITON-TIMI 38 (trial to assess improvement in therapeutic outcomes by optimizing platelet inhibition with prasugrel-thrombolysis in myocardial infarction 38) [clinical trial, phase III; comparative study; journal article; randomized controlled trial; research support, non-U.S. Gov't]. JACC cardiovascular interventions. 2013;6(12):1275-1281. doi: https://doi.org/10. 1016/j.jcin.2013.06.014. PubMed PMID: CN-01000183.

25. Lablanche JM, Leone A, Merkely B, et al. Comparison of the efficacy of rosuvastatin versus atorvastatin in reducing apolipoprotein B/apolipoprotein A-1 ratio in patients with acute coronary syndrome: results of the CENTAURUS study. Archives of cardiovascular diseases 2010;103(3):160-169. doi: https://doi.org/10.1016/j.acvd.2010.01.005. PubMed PMID: 20417447.

26. Mukherjee D, Kline-Rogers E, Fang J, et al. Lack of clopidogrel-CYP3A4 statin interaction in patients with acute coronary syndrome. Heart 2005:91(1):2326. doi: https://doi.org/10.1136/hrt.2004.035014. PubMed PMID: 15604326; PubMed Central PMCID: PMCPmc1768631. eng.

27. Geisler T, Anders N, Paterok M, et al. Platelet response to clopidogrel is attenuated in diabetic patients undergoing coronary stent implantation. Diabetes Care 2007;30(2):372-374. doi: https://doi.org/10.2337/dc06-1625. PubMed PMID: 17259513; eng.

28. Schmidt $M$, Johansen MB, Maeng $M$, et al. Concomitant use of clopidogrel and statins and risk of major adverse cardiovascular events following coronary stent implantation. Br J Clin Pharmacol 2012;74(1):161-170. doi: https://doi.org/10.1111/j.1365-2125.2012.04169.x. PubMed PMID: 22243420; PubMed Central PMCID: PMCPmc3394141. eng.

29. Toso A, De Servi S, Leoncini M, et al. Effects of statin therapy on platelet reactivity after percutaneous coronary revascularization in patients with acute coronary syndrome. J Thromb Thrombolysis 2017; 44(3):355-361. doi: https://doi.org/10.1007/s11239-017-1541-x. PubMed PMID: 28840456; eng.

30. Malmstrom RE, Orstergren J, Jorgensen $L$, et al. Influence of statin treatment on platelet inhibition by clopidogrel - a randomized comparison of rosuvastatin, atorvastatin and simvastatin co-treatment. J Intern Med 2009; 266(5):457-466. doi: https://doi.org/10.1111/j.1365-2796.2009.02119.x. PubMed PMID: WOS:000270660200006.

31. Wenaweser $P$, Windecker S, Billinger M, Cook S, Togni M, Meier B, et al. Effect of atorvastatin and pravastatin on platelet inhibition by aspirin and clopidogrel treatment in patients with coronary stent thrombosis. American journal of cardiology. 2007;99(3):353-6. https://doi.org/10.1016/j.amjcard. 2006.08.036. PMID: CN-00578042.

32. Zhang JR, Wang DQ, Du J, et al. Efficacy of Clopidogrel and clinical outcome when Clopidogrel is Coadministered with atorvastatin and lansoprazole: a prospective, randomized, controlled trial [journal article; randomized controlled trial; research support, non-U.S. Gov't]. Medicine. 2015;94(50):e2262. doi: https:// doi.org/10.1097/MD.0000000000002262. PubMed PMID: CN-01153632.

33. Riondino $S$, Petrini $N$, Donato $L$, et al. Effects of rosuvastatin on platelet inhibition by clopidogrel in cardiovascular patients. J Thromb Thrombolysis 2009;28(2):151-155. doi: https://doi.org/10.1007/s11239-008-0254-6. PubMed PMID: 18636229; eng.

34. Nagavi JB, Gurupadayya B, Anantharaju PG. Omeprazole and atorvastatin reduces the ability of clopidogrel to inhibit platelet aggregation in patients undergoing percutaneous coronary intervention in a tertiary health care system: a prospective drug-drug interaction study [article]. IJC Metabolic and Endocrine 2016;13:35-40. doi: https://doi.org/10.1016/j.jicme.2016.09.004. English.

35. Godino C, Pavon AG. Platelet reactivity in response to loading dose of atorvastatin or rosuvastatin in patients with stable coronary disease before percutaneous coronary intervention: the STATIPLAT randomized study. 2017; 40(8):605-611. doi: https://doi.org/10.1002/clc.22709. PubMed PMID: 28422300.

36. Blagojevic $A$, Delaney JA, Levesque LE, et al. Investigation of an interaction between statins and clopidogrel after percutaneous coronary intervention: a cohort study. Pharmacoepidemiol Drug Saf 2009;18(5):362-369. doi: https:// doi.org/10.1002/pds.1716. PubMed PMID: 19253920; eng.

37. Gorchakova O, von Beckerath N, Gawaz M, et al. Antiplatelet effects of a 600 mg loading dose of clopidogrel are not attenuated in patients receiving atorvastatin or simvastatin for at least 4 weeks prior to coronary artery stenting. Eur Heart J. 2004 Nov;25(21):1898-1902. doi: https://doi.org/10. 1016/j.ehj.2003.10.039. PubMed PMID: 15522468; eng.

38. Poyet $\mathrm{R}$, Cuisset $\mathrm{T}$, Broca FX, et al. Comparison of rosuvastatin and atorvastatin on clopidogrel response and lipidic and inflammatory parameters after coronary stenting for acute coronary syndrome [journal: conference abstract]. Archives of cardiovascular diseases supplements 2012; 4(1):24. PubMed PMID: CN-01473196.

39. Suh JW, Cha MJ, Lee SP, et al. Relationship between statin type and responsiveness to clopidogrel in patients treated with percutaneous coronary intervention: a subgroup analysis of the CILON-T trial [Comparative Study; Journal Article; Randomized Controlled Trial; Research Support, NonU.S. Gov't]. Journal of atherosclerosis and thrombosis. 2014;21(2):140-150. PubMed PMID: CN-00981276.

40. Guo J, Zhang WZ, Zhao Q, Wo JS, Cai SL. Study on the effect of different doses of rosuvastatin on ventricular remodeling in patients with acute coronary syndrome after emergency percutaneous coronary intervention. European review for medical and pharmacological sciences. 2017;21(19): 4457-63. PMID: CN-01617716.

41. Mitsios JV, Papathanasiou Al, Elisaf M, et al. The inhibitory potency of clopidogrel on ADP-induced platelet activation is not attenuated when it is co-administered with atorvastatin ( $20 \mathrm{mg} /$ day) for 5 weeks in patients with acute coronary syndromes [article]. Platelets. 2005;16(5):287-292. doi: https://doi.org/10.1080/09537100400028776. English.

42. Mitsios JV, Papathanasiou Al, Rodis Fl, et al. Atorvastatin does not affect the antiplatelet potency of clopidogrel when it is administered concomitantly for 5 weeks in patients with acute coronary syndromes [clinical trial; journal article; randomized controlled trial]. Circulation. 2004;109(11):1335-1338. doi: https// doi.org/10.1161/01.CIR.0000124581.18191.15. PubMed PMID: CN-00468344.

43. Siepmann T, Heinke D, Kepplinger J, et al. Interaction of clopidogre and statins in secondary prevention after cerebral ischaemia - a randomized, double-blind, double-dummy crossover study [journal article; randomized controlled trial; research support, non-U.S. Gov't]. Br J Clin Pharmacol 2014;78(5):1058-1066. https://doi.org/10.1111/bcp. 12416. PubMed PMID: CN-01040738.

44. Leoncini M, Toso A, Maioli M, et al. High-dose atorvastatin on the pharmacodynamic effects of double-dose clopidogrel in patients undergoing percutaneous coronary interventions: the ACHIDO (atorvastatin and Clopidogrel HIgh DOse in stable patients with residual high platelet activity) study [journal article; randomized controlled trial; research support, non-U.S. Gov't]. JACC cardiovascular interventions. 2013;6(2):169-179. doi: https://doi.org/10.1016/j.jcin.2012.09.013. PubMed PMID: CN-00877266.

45. Motovska Z, Widimsky P, Petr R, et al. Factors influencing clopidogrel efficacy in patients with stable coronary artery disease undergoing elective 
percutaneous coronary intervention: statin's advantage and the smoking "paradox" [journal article; randomized controlled trial; research support, nonU.S. Gov't]. J Cardiovasc Pharmacol 2009;53(5):368-372. doi: https://doi.org/ 10.1097/FJC.0b013e31819d616b. PubMed PMID: CN-00720227.

46. Angiolillo DJ, Alfonso F. Clopidogrel-statin interaction: myth or reality? J Am Coll Cardiol 2007;50(4):296-298. doi: https://doi.org/10.1016/j.jacc.2007.04.041. PubMed PMID: 17659195; eng.

47. Wenaweser $P$, Eshtehardi $P$, Abrecht $L$, et al. A randomised determination of the effect of Fluvastatin and atorvastatin on top of dual antiplatelet treatment on platelet aggregation after implantation of coronary drugeluting stents. The EFA-trial [journal article; randomized controlled trial]. Thromb Haemost 2010;104(3):554-562. doi: https://doi.org/10.1160/TH09-11-0765. PubMed PMID: CN-00768460.

48. Smith SM, Judge HM, Peters $\mathrm{G}$, et al. Multiple antiplatelet effects of clopidogrel are not modulated by statin type in patients undergoing percutaneous coronary intervention. Platelets. 2004 Dec;15(8):465-474. doi: https://doi.org/10. 1080/0953710412331272532. PubMed PMID: 15763887; eng.

49. Kreutz RP, Breall JA, Sinha A, et al. Simultaneous administration of high-dose atorvastatin and clopidogrel does not interfere with platelet inhibition during percutaneous coronary intervention. Clinical pharmacology: advances and applications. 2016;8:45-50. doi: https:/doi.org/10.2147/cpaa.s98790. PubMed PMID: 27350760; PubMed Central PMCID: PMCPmc4902146. eng.

50. Mach F, Senouf $D$, Fontana $P$, et al. Not all statins interfere with clopidogrel during antiplatelet therapy [Journal: Article]. Eur J Clin Investig. 2005;35(8): 476-81. https://doi.org/10.1111/j.1365-2362.2005.01522.x. PubMed PMID: CN-00575330.

51. Piorkowski M, Weikert U, Schwimmbeck PL, et al. ADP induced platelet degranulation in healthy individuals is reduced by clopidogrel after pretreatment with atorvastatin [article]. Thromb Haemost. 2004;92(3):614-20. https://doi.org/10.1160/TH03-12-0738. English

52. Oesterle A, Laufs U, Liao JK. Pleiotropic effects of statins on the cardiovascular system. Circ Res 2017;120(1):229-243. doi: https://doi.org/10 1161/CIRCRESAHA.116.308537. PubMed PMID: 28057795; PubMed Central PMCID: PMC5467317.

53. Giusti B, Abbate R. Response to antiplatelet treatment: from genes to outcome. Lancet. 2010;376(9749):1278-81.

54. Wells QS, Delaney JT, Roden DM. Genetic determinants of response to cardiovascular drugs [review]. Curr Opin Cardiol 2012;27(3):253-261. doi: https://doi.org/10.1097/HCO.0b013e32835220e3. English.

55. Angiolillo DJ, Shoemaker SB, Desai B, et al. Randomized comparison of a high clopidogrel maintenance dose in patients with diabetes mellitus and coronary artery disease: results of the optimizing antiplatelet therapy in diabetes mellitus (OPTIMUS) study. Circulation. 2007;115(6):708-716. doi: https://doi.org/10. 1161/circulationaha.106.667741. PubMed PMID: 17261652; eng.

56. Lotfi A, Schweiger MJ, Giugliano GR, et al. High-dose atorvastatin does not negatively influence clinical outcomes among clopidogrel treated acute coronary syndrome patients--a pravastatin or atorvastatin evaluation and infection therapy-thrombolysis in myocardial infarction 22 (PROVE IT-TIMI 22) analysis [comparative study; journal article; randomized controlled trial]. Am Heart J 2008;155(5):954-958. doi: https:/doi.org/10.1016/j.ahj.2007.12.009. PubMed PMID: CN-00631406.

57. Park JS, Cha KS, Lee HW, et al. Platelet reactivity and clinical outcomes in patients using CYP3A4-metabolized statins with clopidogrel in percutaneous coronary intervention [journal article; multicenter study; randomized controlled trial]. Heart Vessel 2017;32(6):690-699. doi: https:// doi.org/10.1007/s00380-016-0927-6. PubMed PMID: CN-01459270.

Ready to submit your research? Choose BMC and benefit from:

- fast, convenient online submission

- thorough peer review by experienced researchers in your field

- rapid publication on acceptance

- support for research data, including large and complex data types

- gold Open Access which fosters wider collaboration and increased citations

- maximum visibility for your research: over $100 \mathrm{M}$ website views per year

At BMC, research is always in progress.

Learn more biomedcentral.com/submissions 